\title{
Ground-Water Resources at Diego Garcia, 1985-96
}

By Jill D. Torikai

U.S. Department of the Interior

U.S. Geological Survey Water-Resources Investigations Report 01-4087

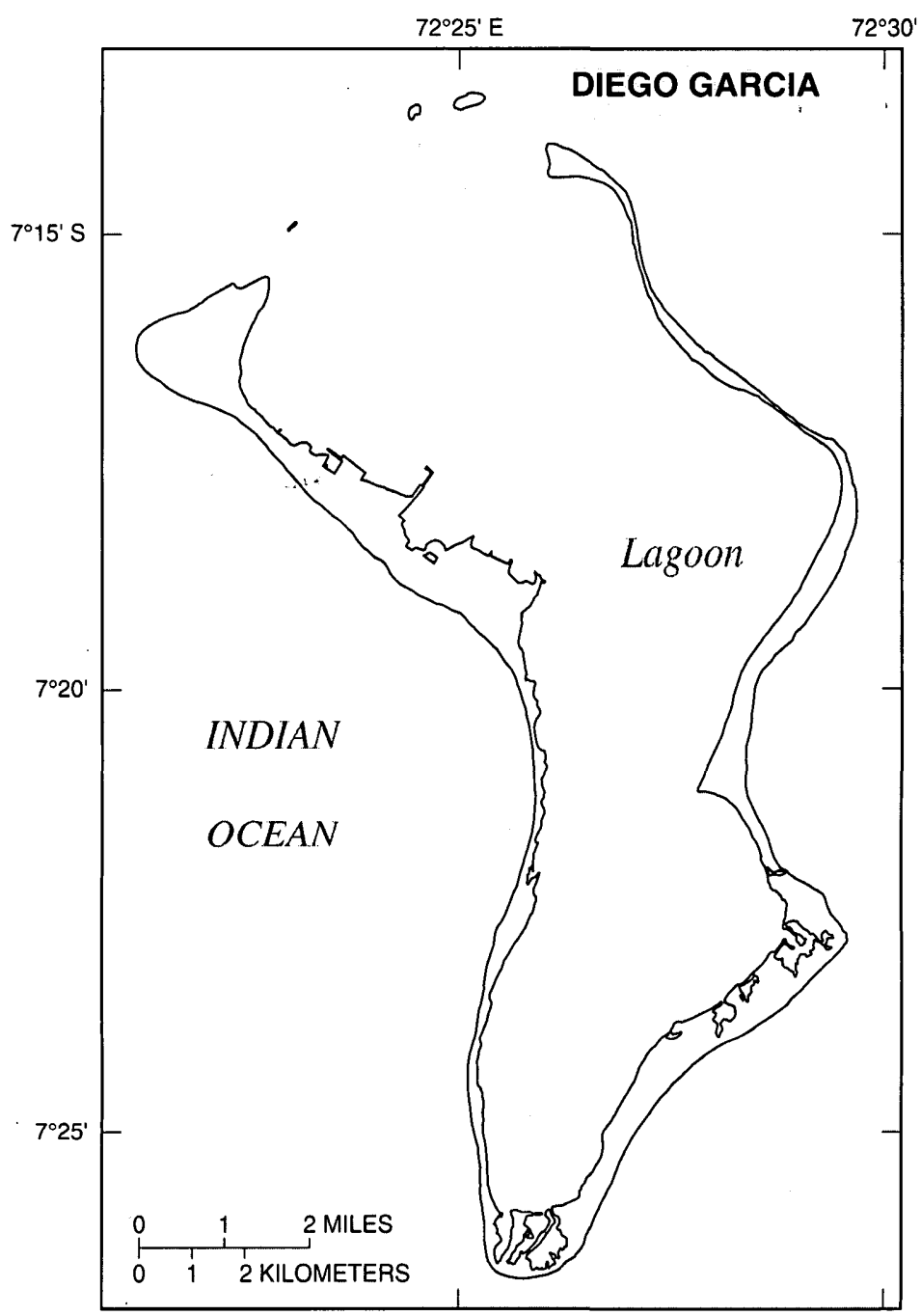

2001

Prepared in cooperation with the

U.S. DEPARTMENT OF THE NAVY, NAVY SUPPORT FACILITY, DIEGO GARCIA

U.S. DEPARTMENT OF THE AIR FORCE, PACIFIC AIR FORCES 